\title{
0720 IGR OF SAFETY POLICY IN KOREA
}

C Kang* Correspondence: Department of Public Administration (Health and Welfare), Dankook University, San 29, Anseo-Dong, Cheonan-Si, Choongnam, Korea

10.1136/ip.2010.029215.720

Background Partnership for safety across sectors is suggested as one of the principles of safe community. IGR (intergovernmental relationships) is very important to improve safety equality among regions and people within a country. However, safety policy in the centralised country is different from that of decentralised country due to the context. Korea is in transit to the decentralised system so that recent experience in IGR for safety policy has implication. II Safety policy in Korea (1) Development of safety policy in Korea Policy target was not injury prevention but disaster control. However, Lee administration established ministry of public administration and security so that safety policy was expanded. In 2009, Korean type of safe community project was launched by national government. By contrast, WHO safe community project has been accomplished by local governments by themselves. (2) IGR of Safety Policy Based on the theoretical perspective, three forms of IGR can be described such as disentangled, federallocal unilateral or collaborative. Despite of fiscal decentralisation since 2007, national government is able to coerce local into delivering a special type of service, which is referred to federal-unilateralism. Korean type of safe community project has been implemented through Special Local Tax Share allocation to nine local government. III. Context Matters both bureaucratic driven and guideline of national government are prevalence in the safety policy process in Korea. IGR of safety policy in Korea reflects the context, short-term local autonomy and experience of development by government, which can be positive to improve the safety equality. 